\title{
Avoiding Over-Diagnosis: Exploring the Role of Gender in Changes over Time in Statistics Anxiety and Attitudes
}

Kelly Rhea MacArthur

University of Nebraska at Omaha, kmacarthur@unomaha.edu

Follow this and additional works at: https://digitalcommons.usf.edu/numeracy

Part of the Gender and Sexuality Commons, and the Medicine and Health Commons

\section{Recommended Citation}

MacArthur, Kelly R.. "Avoiding Over-Diagnosis: Exploring the Role of Gender in Changes over Time in Statistics Anxiety and Attitudes." Numeracy 13, Iss. 1 (2020): Article 4. DOI: https://doi.org/10.5038/ 1936-4660.13.1.4 


\title{
Avoiding Over-Diagnosis: Exploring the Role of Gender in Changes over Time in Statistics Anxiety and Attitudes
}

\begin{abstract}
The importance of quantitative literacy for creating and maintaining a democratic and just society is unequivocal, but undergraduate students often do not acquire these important skills. One barrier to teaching quantitative literacy skills is students' anxiety. The empirical evidence of the extent of the problem, however, does not seem to match anecdotal accounts of instructors who may be "diagnosing" statistics anxiety as universal among students and across different sources of anxiety. The purpose of this study is to identify the specific aspects of statistics anxiety that present barriers to student success by employing the Statistics Anxiety Rating Scale (STARS) to analyze two-wave panel survey data from a sample of 113 undergraduates from eight sections of a Social Statistics course. This study also examines how gender shapes statistics anxiety/attitudes and whether changes over time in anxiety/attitudes are associated with academic performance. Results indicate that a majority of students report elevated levels of exam anxiety compared to the other types of anxiety/attitudes. Women report significantly more anxiety and more negative attitudes than men, but exam anxiety improves over the course of the semester significantly more so for women. Results also indicate that statistics anxiety/attitudes are largely unrelated to academic performance. Results are discussed in the context of their implications for directing attention to specific aspects of statistics anxiety on which to focus pedagogical efforts - to address statistics anxiety/attitudes if necessary, but also to avoid over-diagnosing by not assuming that it applies to all students or all aspects of statistics classes.
\end{abstract}

\section{Keywords}

gender; statistics anxiety, quantitative literacy, STARS

\section{Creative Commons License}

\section{c) (7) (8)}

This work is licensed under a Creative Commons Attribution-Noncommercial 4.0 License

\section{Cover Page Footnote}

Kelly Rhea MacArthur, PhD is faculty at the University of Nebraska Omaha in the Department of Sociology and Anthropology. Dr. MacArthur is a medical sociologist with areas of specialization in medical education, mental health, health disparities, gender, and quantitative methods. Specifically, her current research focuses on the well-being of medical students, the effects of loneliness on health, and statistics pedagogy. 


\section{Introduction}

The importance of quantitative literacy for creating and maintaining a democratic and just society is unequivocal, but undergraduate students often do not acquire these important skills. One barrier to teaching quantitative literacy skills is the level of anxiety that students often feel. The literature identifies various causes and effects of "statistics anxiety," generally defined as "a feeling of anxiety when taking a statistics course or doing statistical analysis; that is gathering, processing, and interpreting data" (Cruise et al. 1985, 92). The empirical evidence, however, does not seem to match instructors' anecdotal accounts who perceive statistics anxiety to be universal among students and develop pedagogical strategies to address it accordingly (DeCesare 2007; Deckard 2017).

There is disagreement as to the extent to which statistics anxiety needs to be addressed at all. On one hand, considerable evidence shows that, because statistics anxiety is so widespread, statistics courses are dreaded and feared (Blalock 1987; Schacht and Stewart 1990; Onwuegbuzie and Wilson 2003; Chew and Dillon 2014). Estimates of the percentage of students in statistics courses who experience anxiety range from 58 percent to a high of 80 percent (Onwuegbuzie and Wilson 2003; DeCesare 2007; Condron et al. 2018). On the other hand, despite a plethora of articles claiming near-universal levels of statistics anxiety (Blalock 1987; Onwuegbuzie and Wilson 2003; Paxton 2006), several scholars have pointed out that students' fear and hatred of statistics is largely exaggerated and untested empirically (DeCesare 2007; Condron et al. 2018). Thus, statistics anxiety should be addressed without inaccurately labeling everything - all attitudes, beliefs, and behaviors - as "anxiety" and making potentially harmful assumptions about the estimated third of students who do not experience any anxiety (Condron et al. 2018).

Given the widespread assumption that statistics anxiety is rampant, the purpose of the current study is to utilize the Statistics Anxiety Rating Scale (STARS) - the most widely used survey instrument to measure statistics anxiety-to empirically assess levels of six different types of anxiety in social statistics courses (Cruise et al. 1985). I also explore how the important structural variable of gender shapes the experience of statistics anxiety over the course of a semester. Specifically, the goals of this study are to explore the following aspects of statistics anxiety and attitudes: Q1) the mean levels of different types; Q2) changes over the course of the semester; Q3) gender differences in mean levels; and Q4) gender differences in changes over time. Additionally, this study, which is largely exploratory given that the data are drawn from a single instructor's classes, addresses two additional research questions regarding the associations between statistics anxiety/attitudes and academic performance: Q5) whether anxiety at the beginning and/or the end of the semester predicts grades, and Q6) whether changes in anxiety from the beginning 
to the end of the semester predict grades. Ultimately, this study seeks to help instructors avoid "over-diagnosing" and possibly inappropriately "treating" their students for statistics anxiety (DeCesare 2007).

\section{Background}

\section{The STARS: Types of Statistics Anxiety and Attitudes}

To clarify the methodological issues that conflate statistics anxiety with exam anxiety, math anxiety, and statistics attitudes, the STARS distinguishes between three different types, or sources, of statistics anxiety: from exams, interpreting mathematical operations, and asking others for help (Cruise et al. 1985). The STARS includes an additional three sub-scales that measure students' attitudes toward statistics teachers, one's own perceived abilities to do mathematical computations, and the perceived worth of statistics in their occupational and everyday lives (Cruise et al. 1985). The STARS instrument and its sub-scales have been extensively validated (Cruise et al. 1985; Baloğlu 2002; Liu et al. 2011; Papousek et al. 2012). Thus, measuring each of the six scales separately helps to identify the specific aspects of statistics anxiety that function as barriers to success in statistics classes.

Studies using the STARS consistently show that, of the three types of anxiety, students report the most severe anxiety surrounding exams (Baloğlu 2003; Baloğlu and Zelhart 2003; Hanna et al. 2008; Keeley et al. 2008; Papousek et al. 2012; Williams 2013; Hedges 2017). A few exceptions find interpreting mathematical calculations produces the most anxiety (Walsh and Ugumba-Agwunobi 2002; Williams 2010). Anxieties from both interpretation and asking for help, especially the former, have been shown to be important sources of anxiety (Onwuegbuzie and Wilson 2003). Studies also produce inconsistent findings as to the relative prevalence rates of the three attitudes' sub-scales: computational self-concept, worth of statistics, and statistics teachers. In a comparison of mean levels of the STARS constructs across four studies, Liu et al. (2011) find that among the four samples, results are mixed as to students' most and least favorable attitudes. In two of the studies, respondents report the most unfavorable attitudes toward the worth of statistics (Onwuegbuzie 2004; Liu et al. 2011) and, in the other two studies, the most negative attitudes are toward their computational self-concept (Walsh and Ugumba-Agwunobi 2002; Baloğlu and Zelhart 2003). These differences in means, however, seem negligible (e.g., a mean of 2.014 compared to 2.019), and it is not known whether they are statistically significant differences.

Taken together, past research suggests that the three types of statistics attitudes - toward teachers, computational self-concept, and worth of statisticsare related to, but distinct from, each other, as well as from the three types of statistics anxiety - exam, interpretation, and asking for help. While research shows 
that they all play an important role in students' experiences in social statistics courses, the relative extent and influence of each of the six types of anxiety/attitudes is less established. To determine if statistics anxiety is truly endemic or if statistics anxiety is being over-diagnosed, there is value in examining if levels are equally high across the six types of STARS anxiety/attitudes constructs. The first research question that this study addresses is: Q1) what is the relative prevalence (i.e., mean levels) of the STARS' six different types of statistics attitudes and anxiety?

\section{Are Statistics Anxiety and Attitudes Stable across the Duration of the Course?}

Despite the large body of literature on pedagogical methods to address statistics anxiety, there is little evidence that they actually reduce anxiety (DeCesare 2007). There is also some evidence that negative attitudes toward statistics may be unamenable to change in the course of one semester (Townsend et al. 1998; Zieffler et al. 2008; Lesser et al. 2016). Few studies are able to make a causal argument regarding change over time in statistics anxiety, as causal reasoning necessitates longitudinal data. Research that does utilize a longitudinal pre- and post-survey design shows inconsistent findings as to whether the STARS anxiety and attitudes constructs improve over the course of the semester. For example, using a modified version of the STARS, one study found that, of seven types of anxiety/attitudes, the only type to significantly worsen was students' perceptions of the worth of statistics while test and interpretation anxiety improved (Zanakis and Valenzi 1997). Other longitudinal studies using the STARS show that statistics anxiety decreases and attitudes improve over the semester (Keeley et al. 2008; Chiesi and Primi 2010; Williams 2013; McGrath et al. 2015). Most studies that examine change in statistics anxiety test the effects of a given intervention, but it is not clear whether statistics anxiety decreases and attitudes improve throughout the semester naturally, in the absence of a specific intervention, as it might when anyone becomes familiar with what was previously mysterious. Thus, the second research question examined here is: Q2) do statistics attitudes and anxiety change over the course of the semester?

\section{Gender Differences in Statistics Anxiety and Attitudes}

Another contribution this study makes to the literature on statistics anxiety is examining variation in the levels/types of anxiety and changes over time by gender. Research that has examined gender differences show inconsistent findings, with some studies finding a greater degree of statistics and math anxiety among women compared to men (Benson 1989; Bradley and Wygant 1998; Onwuegbuzie 1998; DeCesare 2007; Condron et al. 2018), while other studies show mixed or no gender differences (Zeidner 1990; Benson et al. 1994; Townsend et al. 1998; Baloğlu 2003; Haynes et al. 2004; Onwuegbuzie 2004; Van Gundy et al. 2006; Wismath and Worrall 2015). Studies using the STARS constructs show differential effects across 
the six dimensions, with Hedges (2017), for example, finding that women have significantly higher test anxiety and worse computational self-concept than men and Macher et al. (2013) finding that women have elevated rates of anxiety about tests, interpretation, and self-concept compared to men. Even where gender differences in statistics anxiety exist, the effect sizes may be far too small to contain any pedagogical salience (Rodarte-Luna and Sherry 2008). In addition to the mixed results regarding gender differences in mean baseline levels of anxiety, it is also unknown whether women's and men's anxiety changes at different rates throughout the semester. Given the inconsistent findings and overall limited research regarding gender differences in mean levels and changes across the duration of a semester in STARS scales, it is important to address the following third and fourth research questions of this study: Q3) are there gender differences in mean levels of statistics anxiety/attitudes, and Q4) are there gender differences in change over time in statistics anxiety/attitudes?

\section{Statistics Anxiety and Attitudes and Academic Performance}

If levels of different types of statistics anxiety and attitudes are high and if they are able to change over the course of the semester, then the next question is does it matter? The research suggests that it does matter in that anxiety adversely affects learning (Rosenfeld 1978). Two reviews of the causes and effects of statistics anxiety conclude that there is a robust negative relationship between statistics anxiety and various indicators of academic performance (Onwuegbuzie and Wilson 2003; Chew and Dillon 2014) and, in fact, anxiety might be the strongest predictor of grades in statistics classes (Fitzgerald et al. 1996).

Despite the general consensus among scholars that statistics anxiety is negatively related to learning, the relationship seems to be more complicated than just a direct causal relationship. Some studies show no causal relationship between anxiety and academic performance (Lalonde and Gardner 1993; Zanakis and Valenzi 1997; Nasser 2004; Chiesi and Primi 2010). There is even evidence that at least some degree of anxiety can function in a positive manner for academic performance (Onwuegbuzie 1995; Onwuegbuzie and Seaman 1995; Keeley et al. 2008; Macher et al. 2013). These inconsistent findings may be accounted for by the limitations of past research on statistics anxiety.

The first way in which past research is limited is that many studies employ grades as predictors, as opposed to outcomes, of statistics anxiety (Baloğlu 2002; Walsh and Ugumba-Agwunobi 2002; Van Gundy et al. 2006; DeCesare 2007; Chiou et al. 2014; Condron et al. 2018). Second, some past studies measured proxies for academic achievement, such as cardiovascular measures of anxiety during an exam (Papousek et al. 2012) or expected, as opposed to actual, grades in the course (Van Gundy et al. 2006; DeCesare 2007; Condron et al. 2018). This 
limitation is especially important given that Hanna et al. (2008) show that students' levels on the six STARS anxiety dimensions account for a larger proportion of explained variance in predicted test scores compared to actual test scores. Third, another understudied area regarding the relationship between statistics anxiety and academic performance is whether baseline levels, ending levels, and/or change in levels of anxiety matter for learning outcomes. The timing of the assessment of anxiety/attitudes and changes over time may be important variables to consider, as Wisenbaker et al. (2000) found that statistics attitudes assessed at the end of the course had an effect on achievement in the course, but baseline attitudes did not. Zanakis and Valenzi (1997) found conflicting results in that several beginning-ofterm factors, including math anxiety, are associated with final course grade, but not those factors at the end of the term. To address these three issues, the last research questions that this study explores are: Q5) are statistics anxiety/attitudes associated with academic performance, and Q6) are changes in statistics anxiety/attitudes associated with academic performance? In summary, this exploratory study uses a pre- and post-survey design among students in eight sections of a Social Statistics course across four semesters to avoid the "over-diagnoses" of statistics anxiety and instead identify the specific aspects of statistics anxiety and attitudes that warrant "treatment."

\section{Methods Sample/Procedure}

Data for this study were collected from a metropolitan public university with approximately 11,000 full time students in 2018, with about 37 percent of the incoming 2018 class being first generation students and 35 percent "ethnically diverse." Majors both within the arts and sciences (e.g., Sociology, Political Science, Communications, Psychology), as well as outside of it (e.g., Nursing, Business), typically enroll in Social Statistics to fulfill a quantitative literacy requirement, but only Sociology majors are required to take the 1-credit accompanying lab course. The prerequisites for the course are sophomore-standing and a basic math class. Like most introductory level statistics courses, it begins by covering descriptive statistics (e.g., measures of central tendency and dispersion) and then progresses to inferential statistics (e.g., confidence intervals) and culminates in multiple regression techniques. Bricks-and-mortar Social Statistics classes are capped at 25 students each and online courses at 20.

Pre- and post-survey data were collected for this study in eight Social Statistics courses across four consecutive semesters from Fall 2016 through Spring 2018. All classes were taught by the author and were held for an hour and fifteen minutes, twice a week. The pre-survey data were collected during the class after the first week of class when the enrollment period had closed. The post-survey data was 
collected on the last day of class before final exam week when all students had to be there in order to receive the paper copy of the take-home exam. This study complied with all IRB regulations and the surveys were anonymous, voluntary, and students were given obtained consent information (IRB\#: 863-16-EX).

Although it is not possible to calculate the exact response rate across the eight classes of the 199 students enrolled at Time 2, 196 completed the survey, which constitutes an approximate 98 percent response rate. However, complete data (matching pre- and post-surveys and not missing on any of the analytic variables) was obtained for 113 students, which constitutes an approximate 57 percent response rate. Thus, there is a considerable amount of missing data. Missing data from Time 1 to Time 2 (or vice versa) is due to a variety of reasons, including students who 1) dropped the course; 2) were absent from class on the day the preand/or post-survey was administered; 3 ) chose not to complete either/both the preor post-survey; or 4) did not correctly write the last 4 digits of their student ID number on one of the surveys. A missing data analysis using independent samples $t$-tests on all analytic variables revealed that those with lower exam scores and lower final course grades were significantly more likely to be missing $(p<0.000)$. At T1, those who had more anxiety about interpretation and worse attitudes toward teachers and self-concept $(p<0.05)$ were significantly more likely to be missing, but no $\mathrm{T} 2$ variables were more likely to be missing. I deleted any observation from the dataset that was missing on any of the analytic variables (i.e., listwise deletion), which is the most robust method for dealing with data on the independent variables that are not missing at random (Allison 2001). The analytic sample with no missing data consists of 113 students, 81 women and 32 men.

\section{Measures}

Dependent Variables. I measure two dependent variables: Exam Grades and Final Grade. Students' exam grades constitute slightly less than half (about 49 percent) of their final grade in the course. Exam Grades is measured by the percent of the possible 350 points across three exams (worth 100, 100, and 150 points each), and Final Grade is the final percentage grade that students earned in the course, including their exam grades. The other portion of their final grade is about 31 percent homework assignments and 21 percent participation, which is measured by daily "clicker" questions that students answer during class. I also tend to offer a few extra credit assignments throughout the semester.

The Statistics Anxiety Rating Scale (STARS). The Statistics Anxiety Rating Scale (STARS) (Cruise et al. 1985) is the most commonly used measure of statistics anxiety (Hanna et al. 2008). The 51-item scale has been validated and shown to have six sub-scales: Worth of Statistics, Interpretation Anxiety, Test and Class Anxiety, Computational Self-concept, Fear of Asking for Help, and Fear of Statistics Teachers (Cruise et al. 1985; Baloğlu 2002; Hanna et al. 2008). The first 
three subscales are types of anxiety measured on a 3-point Likert scale with responses $1=$ "no anxiety," $2=$ "some anxiety," and $3=$ "strong anxiety." The other three scales are attitudes measured on a 5-point Likert scale with responses ranging from $1=$ "strongly agree" to $5=$ "strongly disagree." Some items are reverse-coded so that, for all of the scales, higher scores indicate higher levels of anxiety and more negative attitudes. For the portion of the analyses that examine change in these six constructs, I created change scores by subtracting the mean value of each Time 1 scale from the Time 2 value.

The Exam/Class Anxiety subscale contains 8 items with high internal consistency at T1 (alpha $=0.872$ ) that measures students' anxiety when taking a test or attending a class. Anxiety about interpreting statistical results, "Interpretation Anxiety," contains 11 items and has a T1 Cronbach's alpha of 0.820. Fear about Asking for Help is a 4-item scale with an alpha of 0.844. The three sub-scales measured on a five-point Likert scale are measures of attitudes about their personal ability to do mathematical calculations ("Self-concept"), statistics teachers ("Teachers"), and the perceived usefulness of statistics ("Worth"), with T1 alphas of 0.849 (7 items), 0.844 (5 items), and 0.939 (16 items), respectively.

Gender. Gender is coded 1=Female and $0=$ Male. Students' gender was determined by their name and picture. It should be noted that this measure of gender is not ideal in that it only represents stereotypical presentations of gender and captures neither how students self-identify nor non-binary gender identities.

Controls. Given that non-whites are shown to have higher rates of statistics anxiety (Onwuegbuzie 1999), I control for race. Race/Ethnicity is coded 1=White and $0=$ Nonwhite, as determined by their picture. As with gender, this measure of race/ethnicity does not reflect how students self-identify.

Semester is a set of dummy variables coded as 0 or 1 with the first semester of data collection, Fall 2016, used as the omitted category. These dummy variables control for differences in the course and external factors in each semester, accounting for variation in anxiety/attitudes and grades for both factors I could not control, such as the weather and the structure of the classroom, as well as improvements I made to the course as I gained experience with each semester.

Statistics Lab is a dichotomous variable measured 1=Yes, in lab class, and $0=$ Not in lab class. Because only Sociology majors are required to take the accompanying Statistics Lab course, this variable also distinguishes a sociology major from a non-major.

\section{Data Analysis}

To determine baseline levels and types of statistics attitudes and anxiety (Q1), I report descriptive statistics (means and standard deviations). I then employ a series of 2 (time) by 2 (gender) mixed analysis of variance (ANOVA) to answer Q2 
through Q4 to explore whether the three types of anxiety and three types of attitudes significantly changed from $\mathrm{T} 1$ to $\mathrm{T} 2$ and whether there are gender differences in mean levels and/or the changes over time. Time (T1 and T2) is the within-subjects factor and gender (women and men) is the between-subjects factor. Effect sizes are determined with partial eta-squared $\left(\eta_{p}{ }^{2}\right)$ reported in Table 4 as a percentage of variance explained in the dependent variable by the independent variable controlling for the variance accounted for by the other variables.

I then run a series of regression models to address research questions 5 and 6 that are meant to explore the potential relationships between statistics anxiety/attitudes and academic performance at $\mathrm{T} 1$, at $\mathrm{T} 2$, and changes from $\mathrm{T} 1$ to T2 in statistics anxiety/attitudes. First, I run four ordinary least squares regression (OLS) models with exam grades and final course grade as dependent variables for $\mathrm{T} 1$ and $\mathrm{T} 2$. I then run two additional models to examine change from $\mathrm{T} 1$ to $\mathrm{T} 2$ as the independent variable to predict academic performance. In addition to gender, all models control for race/ethnicity, semester, and enrollment in the accompanying statistics lab course. Statistical significance for all analyses is set at $p<0.05$.

\section{Results}

\section{Descriptive Statistics}

Descriptive Statistics for the full sample of 113 students are reported in Table 1. The sample is primarily women $(71.7 \%)$ and white $(84.1 \%)$. Respondents average 81.58 percent $(S D: 11.83)$ on exams grades and 87.81 percent $(S D: 10.12)$ on final course grade. Students in the sample are drawn about evenly from the four semesters of data collection, with less than a quarter of them being in the accompanying Statistics Lab class and, therefore, Sociology majors (22.1\%).

\begin{tabular}{|c|c|c|}
\hline Variable & $N(\%)$ & Range \\
\hline \multicolumn{3}{|l|}{ Grades } \\
\hline Exam Grades & $81.58(11.83)$ & $0-100 \%$ \\
\hline Final Grades & $87.81(10.12)$ & $0-100 \%$ \\
\hline \multicolumn{3}{|l|}{ Controls } \\
\hline Gender & $81(71.7 \%)$ & $1=$ Female \\
\hline Race/Ethnicity & $95(84.1 \%)$ & 1= White \\
\hline \multicolumn{3}{|l|}{ Semester } \\
\hline Fall 2016 & $32(28.3 \%)$ & $1=$ Yes \\
\hline Spring 2017 & $32(28.3 \%)$ & $1=$ Yes \\
\hline Fall 2017 & $24(21.2 \%)$ & $1=$ Yes \\
\hline Spring 2018 & $25(22.1 \%)$ & $1=$ Yes \\
\hline Stats Lab & $25(22.1 \%)$ & $1=$ in lab \\
\hline
\end{tabular}


Table 2

STARS Sub-Scale Bivariate Correlations $(N=113)$

\begin{tabular}{|c|c|c|c|c|c|c|c|c|c|c|c|c|c|c|}
\hline & 1. & 2. & 3. & 4. & 5. & 6. & 7. & 8. & 9. & 10. & 11. & 12. & 13. & 14. \\
\hline \multicolumn{15}{|l|}{ Anxiety } \\
\hline 1. Exam $\mathrm{T} 1$ & 1 & & & & & & & & & & & & & \\
\hline 2. Exam T2 & $0.545^{* * *}$ & 1 & & & & & & & & & & & & \\
\hline 3. Interpretation $\mathrm{T} 1$ & $0.628^{* * *}$ & $0.344 * * *$ & 1 & & & & & & & & & & & \\
\hline 4. Interpretation $\mathrm{T} 2$ & $0.324 * * *$ & $0.540 * * *$ & $0.419^{* * *}$ & 1 & & & & & & & & & & \\
\hline 5. Help Asking T1 & $0.259^{* *}$ & 0.141 & 0.183 & 0.143 & 1 & & & & & & & & & \\
\hline 6. Help Asking T2 & 0.123 & $0.421 * * *$ & 0.035 & $0.389 * * *$ & $0.550 * * *$ & 1 & & & & & & & & \\
\hline \multicolumn{15}{|l|}{ Attitudes $^{\mathrm{a}}$} \\
\hline 7. Self-Concept T1 & 0.417 *** & $0.305^{* *}$ & $0.204 *$ & 0.098 & 0.089 & 0.063 & 1 & & & & & & & \\
\hline 8. Self-Concept T2 & $0.225^{*}$ & $0.470 * * *$ & 0.120 & $0.305^{* *}$ & 0.067 & $0.281 * *$ & $0.693^{* * *}$ & 1 & & & & & & \\
\hline 9. Teachers T1 & $0.233^{*}$ & $0.239^{*}$ & 0.184 & 0.161 & 0.062 & $0.220^{*}$ & $0.529 * * *$ & $0.408^{* * * *}$ & 1 & & & & & \\
\hline 10. Teachers T2 & 0.160 & $0.443^{* * *}$ & 0.035 & $0.289^{* *}$ & -0.011 & $0.355^{* * *}$ & $0.354 * * *$ & $0.581^{* * * *}$ & $0.493^{* * *}$ & 1 & & & & \\
\hline 11. Statistics Worth $\mathrm{T} 1$ & $0.227^{*}$ & 0.154 & 0.162 & 0.382 & 0.053 & -0.004 & $0.667 * * *$ & $0.472 * * *$ & $0.542 * * *$ & 0.167 & 1 & & & \\
\hline 12. Statistics Worth $\mathrm{T} 2$ & 0.105 & $0.308^{* *}$ & $0.039^{*}$ & $0.216^{*}$ & -0.045 & 0.088 & $0.540^{* * *}$ & $0.682 * * *$ & $0.396^{* * *}$ & $0.476^{* * *}$ & $0.731 * * *$ & 1 & & \\
\hline \multicolumn{15}{|l|}{ Academic Performance } \\
\hline 13. Exam Grades & $-0.024 * * *$ & $-0.268 * *$ & -0.026 & $-0.239^{*}$ & -0.063 & $-0.226^{*}$ & -0.177 & $-0.363 * * *$ & $-0.269 * *$ & $-0.317 * * *$ & -0.039 & $-0.205^{*}$ & 1 & \\
\hline 14. Final Grade & 0.073 & $-0.213^{*}$ & 0.033 & -0.146 & -0.111 & $-0.265^{* *}$ & -0.087 & $-0.314 * *$ & $-0.236^{*}$ & $-0.306^{* *}$ & 0.025 & -0.141 & $0.892 * * *$ & 1 \\
\hline
\end{tabular}

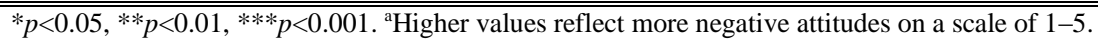


Table 2 displays the bivariate correlations for each of the six STARS subscales. Taken together, all of the bivariate correlations provide support that the scales represent distinct constructs as most of the correlations between the scales are moderate $(r=+0.3-0.5)$ using Cohen's standards (1988). None of the correlations between the scales within T1 or within T2 are strong $(r>0.7)$, although the relationship between $\mathrm{T} 2$ self-concept and worth of statistics is moderately strong $(r=0.682)$. Confirmatory factor analysis using structural equation modeling (SEM) also confirms the validity of these scales and the fit of the measurement model (analyses not shown).

Table 3

STARS Sub-Scales Descriptive Statistics $(N=113)$

\begin{tabular}{lccc}
\hline Anxiety Scale & Cronbach's alpha & $\boldsymbol{M}(\mathbf{S D})$ & $\begin{array}{c}\text { \% No } \\
\text { Anxiety }^{\mathrm{a}}\end{array}$ \\
\hline Exam T1 & 8 items, $a=0.872$ & $2.02(0.48)$ & $45.1 \%$ \\
Exam T2 & 8 items, $a=0.833$ & $1.85(0.47)$ & $56.6 \%$ \\
Interpretation T1 & 11 items, $a=0.820$ & $1.63(0.35)$ & $80.5 \%$ \\
Interpretation T2 & 11 items, $a=0.803$ & $1.50(0.32)$ & $91.2 \%$ \\
Help Asking T1 & 4 items, $a=0.844$ & $1.54(0.55)$ & $72.6 \%$ \\
Help Asking T2 & 4 items $a=0.851$ & $1.39(0.47)$ & $77.9 \%$ \\
\hline Attitudes Scale & Cronbach's alpha & $\boldsymbol{M ( S D )}$ & $\begin{array}{c}\text { \% Positive } \\
\text { Attitudes }\end{array}$ \\
\hline Self-Concept T1 & 7 items, $a=0.849$ & $2.18(0.80)$ & $81.4 \%$ \\
Self-Concept T2 & 7 items, $a=0.838$ & $2.09(0.77)$ & $83.2 \%$ \\
Teachers T1 & 5 items, $a=0.844$ & $1.84(0.68)$ & $92.0 \%$ \\
Teachers T2 & 5 items, $a=0.889$ & $1.91(0.83)$ & $85.0 \%$ \\
Statistics Worth T1 & 16 items, $a=0.939$ & $2.21(0.74)$ & $83.2 \%$ \\
Statistics Worth T2 & 16 items, $a=0.942$ & $2.23(0.79)$ & $78.8 \%$ \\
\hline \hline
\end{tabular}

aPercent "No Anxiety" is determined by the cumulative percentage who scored an average lower than 2 on the scale, ranging from 1-3. "Higher values reflect more negative attitudes on a scale of $1-5$. "Percent "Positive Attitudes" is determined by the cumulative percent who scored an average lower than 3 on the scale, ranging from $1-5$.

Research Question 1: Levels and Types of Statistics Anxiety/Attitudes. In addition to the Cronbach's alphas reported in Table 3 showing acceptable levels of internal consistency for all six of the subscales and for both $\mathrm{T} 1$ and $\mathrm{T} 2$ ranging from $r=0.803$ to $r=0.942$, means and standard deviations of each sub-scale are shown in Table 3. Of the three types of anxiety, students report the most anxiety around exams at both T1 and T2 (Mean: 2.02, SD: 0.48; Mean: 1.85, SD: 0.47) and the least anxiety regarding asking for help at T1 and T2 (Mean: 1.54, SD: 0.55; Mean: 
1.39, SD: 0.47). Among the three types of attitudes, at both $\mathrm{T} 1$ and $\mathrm{T} 2$, students report the most positive attitudes toward statistics teachers (Mean: 1.84, SD: 0.68; Mean: 1.91, SD: 0.83) and the most negative attitudes toward worth of statistics (Mean: 2.21, SD: 0.74; Mean: 2.23, SD: 0.79).

While less than half of respondents $(45.1 \%)$ report "no anxiety" on average in exam anxiety (less than an average of 2 on the scale ranging from 1-3), approximately 81 and 73 percent report no anxiety at T1 regarding interpretation and asking for help, respectively. The majority of students, on average, have positive attitudes (an average of under 3 on the scale ranging from 1-5), with 81.4, 92, and 83.2 percent having positive attitudes toward self-concept, statistics teachers, and worth of statistics, respectively, at T1.

\section{Mixed Analysis ANOVA}

Research Question 2: Changes over Time in Statistics Anxiety/Attitudes. The 2 (time) by 2 (gender) ANOVA analysis results with time (T1 vs. T2) as the withinsubjects factor and gender (women vs. men) as the between-subjects factor are shown in Table 4. The three types of anxiety significantly changed from the beginning to the end of the semester, while the three types of attitudes did not. That is, anxiety around exams $(F=6.73, p=0.011)$, interpretation $(F=8.83, p=0.004)$, and asking for help $(F=5.49, p=0.021)$ significantly improved over the semester; these relationships are weak to moderate $\left(\eta^{2}=0.057,0.074\right.$, and 0.047 , respectively). Attitudes, however, toward self-concept $(\mathrm{F}=0.294, \mathrm{p}=0.589)$, teachers $(F=0.824$, $p=0.366)$, and worth of statistics $(F=3.39, p=0.068)$ do not significantly change from $\mathrm{T} 1$ to $\mathrm{T} 2$; these attitudes have weak relationships with change over time $\left(\eta^{2}=0.003,0.007\right.$, and 0.03 , respectively).

Research Question 3: Gender Differences in Levels/Types. As shown in Table 4 , main effects for gender are statistically significant for exam $(F=10.69, p=0.001)$ and interpretation anxiety $(F=13.20, p<0.000)$, with the descriptive data in Table 4 showing that women reporting significantly more exam and interpretation anxiety than men. These relationships are moderate in strength, with approximately $9 \%$ $\left(\eta_{p}{ }^{2}=0.088\right)$ of the variation in exam anxiety and $11 \%$ in interpretation anxiety $\left(\eta^{2}=0.106\right)$ explained by gender. However, because Box's Test of Equality of Covariance Matrices is statistically significant for interpretation anxiety (Box's $M=11.57, F=3.76, p=0.010$ ), the assumption of homogeneity is violated and thus the statistically significant effect for interpretation anxiety may not be robust. However, another test of the homogeneity assumption, Levene's Test of Equality of Error Variances, is not statistically significant for T1 or T2 interpretation anxiety ( $p=0.107, p=0.570$ ), providing evidence that, conversely, there may not be a significant difference in the variances in interpretation anxiety between women and men. 
Table 4

2 (time) by 2 (gender) Mixed Analysis ANOVA for Statistics Anxiety/Attitudes, Gender, and Change (N=113)

\begin{tabular}{|c|c|c|c|c|c|c|c|c|c|c|}
\hline \multirow[b]{3}{*}{ Variable } & \multicolumn{2}{|c|}{ Time 1} & \multicolumn{2}{|c|}{ Time 2} & \multicolumn{6}{|c|}{ ANOVA Results $(d f: 1,111)$} \\
\hline & \multirow{2}{*}{$\begin{array}{c}\text { Women } \\
(N=81) \\
\text { Mean } \\
(\mathrm{SD})\end{array}$} & \multirow{2}{*}{$\begin{array}{c}\text { Men } \\
(N=32) \\
\text { Mean } \\
(\mathrm{SD})\end{array}$} & \multirow{2}{*}{$\begin{array}{c}\begin{array}{c}\text { Women } \\
(N=81)\end{array} \\
\text { Mean } \\
(\mathrm{SD})\end{array}$} & \multirow{2}{*}{$\begin{array}{c}\begin{array}{c}\text { Men } \\
(N=32)\end{array} \\
\text { Mean } \\
(\mathrm{SD})\end{array}$} & \multicolumn{2}{|c|}{ Gender } & \multicolumn{2}{|c|}{ Change } & \multicolumn{2}{|c|}{ Interaction } \\
\hline & & & & & $\begin{array}{c}F \\
\left(\eta^{2}\right)\end{array}$ & $\begin{array}{c}p- \\
\text { value }\end{array}$ & $\begin{array}{c}F \\
\left(\eta^{2}\right)\end{array}$ & $\begin{array}{c}p- \\
\text { value }\end{array}$ & $\begin{array}{c}F \\
\left(\eta^{2}\right)\end{array}$ & $\begin{array}{c}p- \\
\text { value }\end{array}$ \\
\hline Anxiety & & & & & & & & & & \\
\hline Exam/Class & $\begin{array}{l}2.13 \\
(0.45)\end{array}$ & $\begin{array}{l}1.75 \\
(0.45)\end{array}$ & $\begin{array}{l}1.90 \\
(0.42)\end{array}$ & $\begin{array}{c}1.74 \\
(0.58)\end{array}$ & $\begin{array}{c}10.69 \\
(8.8 \%)\end{array}$ & $0.001 * *$ & $\begin{array}{c}6.73 \\
(5.7 \%)\end{array}$ & $0.011^{*}$ & $\begin{array}{c}5.88 \\
(5.0 \%)\end{array}$ & $0.017^{*}$ \\
\hline Interpretation & $\begin{array}{c}1.71 \\
(0.35)\end{array}$ & $\begin{array}{c}1.44 \\
(0.28)\end{array}$ & $\begin{array}{c}1.54 \\
(0.31)\end{array}$ & $\begin{array}{c}1.40 \\
(0.31)\end{array}$ & $\begin{array}{l}13.20 \\
(10.6 \%)\end{array}$ & $0.000 * * *$ & $\begin{array}{c}8.83 \\
(7.4 \%)\end{array}$ & $0.004 * *$ & $\begin{array}{c}3.09 \\
(2.7 \%)\end{array}$ & 0.081 \\
\hline $\begin{array}{l}\text { Asking for } \\
\text { Help }\end{array}$ & $\begin{array}{l}1.56 \\
(0.56)\end{array}$ & $\begin{array}{c}1.49 \\
(0.56)\end{array}$ & $\begin{array}{l}1.37 \\
(0.46)\end{array}$ & $\begin{array}{l}1.45 \\
(0.49)\end{array}$ & $\begin{array}{c}0.000 \\
(0.0 \%)\end{array}$ & 0.997 & $\begin{array}{c}5.49 \\
(4.7 \%)\end{array}$ & $0.021 *$ & $\begin{array}{c}0.982 \\
(1.8 \%)\end{array}$ & 0.158 \\
\hline $\begin{array}{l}\text { Attitudes }{ }^{\mathrm{a}} \text { Self- } \\
\text { Concept }\end{array}$ & $\begin{array}{c}2.30 \\
(0.80)\end{array}$ & $\begin{array}{l}1.86 \\
(0.69)\end{array}$ & $\begin{array}{l}2.16 \\
(0.78)\end{array}$ & $\begin{array}{c}1.94 \\
(0.73)\end{array}$ & $\begin{array}{c}4.99 \\
(4.3 \%)\end{array}$ & $0.028 *$ & $\begin{array}{c}0.294 \\
(0.03 \%)\end{array}$ & 0.589 & $\begin{array}{c}3.02 \\
(2.7 \%)\end{array}$ & 0.085 \\
\hline $\begin{array}{l}\text { Statistics } \\
\text { Teachers }\end{array}$ & $\begin{array}{c}1.84 \\
(0.64)\end{array}$ & $\begin{array}{c}1.84 \\
(0.78)\end{array}$ & $\begin{array}{c}1.91 \\
(0.77)\end{array}$ & $\begin{array}{c}1.92 \\
(0.97)\end{array}$ & $\begin{array}{c}0.003 \\
(0.0 \%)\end{array}$ & 0.957 & $\begin{array}{c}0.824 \\
(0.07 \%)\end{array}$ & 0.366 & $\begin{array}{c}0.004 \\
(0.0 \%)\end{array}$ & 0.949 \\
\hline $\begin{array}{l}\text { Statistics } \\
\text { Worth }\end{array}$ & $\begin{array}{r}2.34 \\
(0.74) \\
\end{array}$ & $\begin{array}{r}1.87 \\
(0.62) \\
\end{array}$ & $\begin{array}{r}2.39 \\
(0.83) \\
\end{array}$ & $\begin{array}{c}2.05 \\
(0.63) \\
\end{array}$ & $\begin{array}{c}7.81 \\
(6.6 \%) \\
\end{array}$ & $0.006^{* *}$ & $\begin{array}{c}3.39 \\
(3.0 \%) \\
\end{array}$ & 0.068 & $\begin{array}{c}1.31 \\
(1.2 \%) \\
\end{array}$ & 0.254 \\
\hline
\end{tabular}

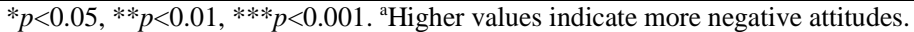

The ANOVA results and the descriptive statistics (means and standard deviations) displayed in Table 4 indicate that women have significantly worse attitudes toward their self-concept $(F=4.99, p=0.028)$ and evaluate the worth of statistics as lower than men do $(F=7.81, p=0.006)$. The effect of gender on selfconcept is weak $\left(\eta_{p}{ }^{2}=0.043\right)$, while the effect on statistics worth is moderate $\left(\eta_{p}{ }^{2}=0.066\right)$. No significant main effects for gender are found for asking for help anxiety $(F=5.49, p=0.997)$ or attitudes toward statistics teachers $(F=3.39$, $p=0.957)$.

Research Question 4: Gender Differences in Change over Time. The ANOVA results in Table 4 also show the interaction between gender and change over time in the various types of statistics anxiety/attitudes. While exam, interpretation, and asking for help anxiety all significantly improve over the course of semester overall and among just women, the only significant interaction effect with gender is with exam/class anxiety $(F=6.73, p=0.011)$ in that women's anxiety surrounding exams significantly decreases compared to their male counterparts. Five percent of the variation in exam anxiety is explained by the interaction between gender and time $\left(\eta_{p}{ }^{2}=0.050\right)$. Figure 1 displays the visualization of this interaction in which women's exam anxiety is significantly higher than men's at baseline, but markedly decreases from T1 to T2, while men's exam anxiety, albeit lower than women's 
anxiety overall, does not change by the end of the semester. Although exam anxiety is the only type that significantly improves more so for women than for men, it should be noted that all three types of anxiety significantly improve over the course of the semester, which can be accounted for almost entirely by women's high levels at T1 that become more similar to men's by T2.

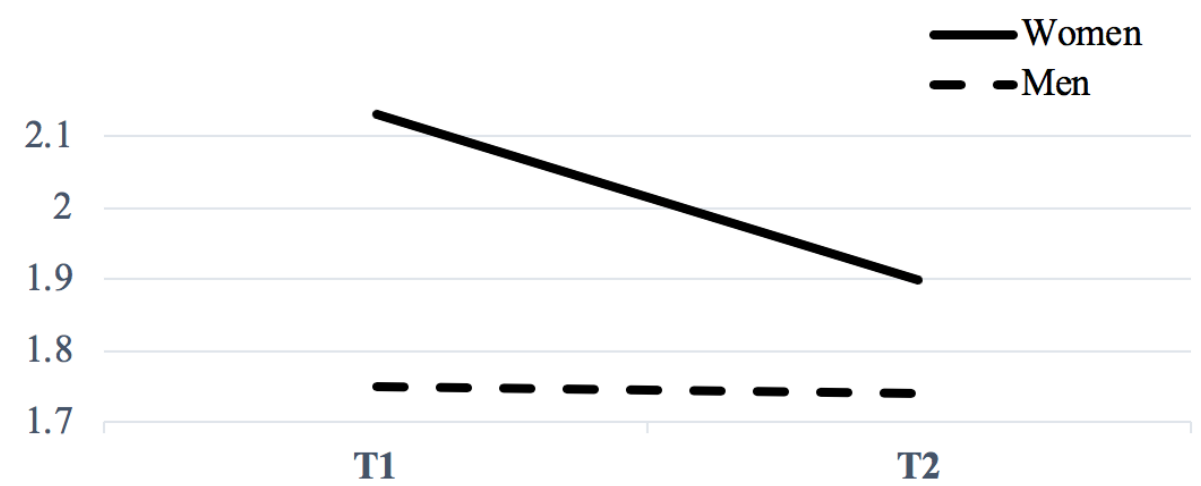

Figure 1. Gender and change in exam anxiety over time.

\section{Exploratory Ordinary Least Squares (OLS) Regression}

Research Questions 5 and 6: Associations with Academic Performance. In addition to the ANOVA analyses, I also explore additional research questions to explore potential relationships between T1, T2, and changes in statistics anxiety/attitudes and two measures of academic performance, exam grades (the average of three exams) and final course grade (the average of exam grades, assignments, "clickers," and extra credit). Unstandardized coefficients, standard errors, standardized coefficients, and $p$-values for each of the four OLS regression models are reported in Table 5. In addition to gender, all models control for race/ethnicity, semester, and enrollment in the accompanying statistics lab course. Baseline levels of anxiety/attitudes, controlling for the other variables, explains $8.8 \%$ of the variation in exam grades and $8.9 \%$ of the variation in final course grade. $\mathrm{T} 2$ anxiety/attitudes explain more variance than T1, with the models explaining $18.1 \%$ and $16.4 \%$ of the variation in exam and final grades, respectively.

As shown in Table 5, the regression results for the relationships between baseline levels of statistics anxiety/attitudes indicate that positive attitudes toward statistics teachers is associated with better exam grades $(b=4.80, p=0.025)$ and final grades $(b=-4.19, p=0.022)$. Neither gender, any of the controls, nor any of the five other types of statistics anxiety/attitudes are significantly related to either of the two measures of academic performance. In comparing the standardized coefficients, however, the results suggest that, in addition to attitudes toward teachers ( $\beta=-0.274, \beta=-0.280)$, the relationships between self-concept and exam $(\beta=-2.15)$ and final grades $(\beta=-0.173)$ are also relatively strong, although not statistically significant $(p=0.121, p=0.210)$. 
Table 5

OLS Regression of Academic Performance on Statistics Attitudes and Anxiety ( $N=113$ )

\begin{tabular}{|c|c|c|c|c|c|c|c|c|c|c|c|c|c|c|c|c|}
\hline \multirow[b]{3}{*}{ Variable } & \multicolumn{8}{|c|}{ Time 1} & \multicolumn{8}{|c|}{ Time 2} \\
\hline & \multicolumn{4}{|c|}{ Exam Grades } & \multicolumn{4}{|c|}{ Final Grade } & \multicolumn{4}{|c|}{ Exam Grades } & \multicolumn{4}{|c|}{ Final Grade } \\
\hline & $b$ & $(S E)$ & $\beta$ & $p$-value & $b$ & $(S E)$ & $\beta$ & $p$-value & $b$ & $(S E)$ & $\beta$ & $p$-value & $b$ & $(S E)$ & $\beta$ & $p$-value \\
\hline Constant & 85.82 & (7.17) & & $0.000^{* * * *}$ & 90.87 & $(6.14)$ & & $0.000^{* * * *}$ & 72.60 & 4.15 & & $0.000^{* * * *}$ & 94.63 & $(6.16)$ & & $0.000^{* * * *}$ \\
\hline \multicolumn{17}{|l|}{ Controls } \\
\hline Gender ( $1=$ female) & 5.16 & $(2.88)$ & 0.197 & 0.076 & 4.21 & $(2.46)$ & 0.188 & 0.091 & 6.29 & $(2.51)$ & 0.240 & $0.014 *$ & 5.39 & $(2.17)$ & 0.241 & $0.015^{*}$ \\
\hline \multicolumn{17}{|l|}{ Semester ${ }^{\mathrm{a}}$} \\
\hline Spring 2017 & 2.17 & (3.08) & 0.083 & 0.482 & -0.632 & $(2.64)$ & -0.028 & 0.811 & 1.05 & $(3.12)$ & 0.040 & 0.737 & -0.651 & $(2.70)$ & -0.029 & 0.810 \\
\hline Fall 2017 & 5.25 & $(3.20)$ & 0.182 & 0.104 & 3.60 & (2.73) & 0.146 & 0.191 & 2.64 & (3.26) & 0.092 & 0.420 & 2.90 & $(2.82)$ & 0.118 & 0.305 \\
\hline Spring 2018 & 3.88 & $(3.25)$ & 0.137 & 0.235 & 1.64 & $(2.78)$ & 0.067 & 0.556 & 4.06 & $(3.37)$ & 0.143 & 0.231 & 2.41 & $(2.92)$ & 0.099 & 0.410 \\
\hline Stats Lab (1=yes) & -2.24 & (2.72) & -0.079 & 0.411 & -0.842 & $(2.32)$ & -0.035 & 0.718 & -1.79 & $(2.52)$ & -0.063 & 0.479 & -0.599 & $(2.18)$ & -0.025 & 0.784 \\
\hline \multicolumn{17}{|l|}{ Anxiety } \\
\hline Exam/Class & 0.854 & $(3.27)$ & 0.035 & 0.794 & 2.79 & (2.79) & 0.132 & 0.320 & -2.94 & $(2.10)$ & -0.117 & 0.329 & -1.92 & (2.59) & -0.089 & 0.461 \\
\hline Interpretation & -2.21 & $(4.17)$ & -0.063 & 0.614 & -2.56 & (3.57) & -0.089 & 0.475 & -2.13 & (4.53) & -0.057 & 0.640 & 0.833 & $(3.92)$ & 0.026 & 0.832 \\
\hline Asking for Help & -0.578 & (2.04) & -0.027 & 0.777 & -1.95 & (1.74) & -0.106 & 0.267 & -1.27 & $(2.65)$ & -0.050 & 0.632 & -2.61 & $(2.29)$ & -0.120 & 0.258 \\
\hline \multicolumn{17}{|l|}{ Attitudes $^{\mathrm{b}}$} \\
\hline Self-Concept & -3.19 & $(2.04)$ & -0.215 & 0.121 & -2.20 & $(1.75)$ & -0.173 & 0.210 & -4.31 & $(2.23)$ & 0.280 & $0.045^{*}$ & -3.53 & $(1.84)$ & -0.268 & 0.058 \\
\hline Teachers & -4.80 & $(2.10)$ & -0.274 & $0.025^{*}$ & -4.19 & $(1.80)$ & -0.280 & $0.022 *$ & -0.841 & (1.66) & -0.059 & 0.613 & -1.06 & (1.43) & -0.086 & 0.463 \\
\hline Statistics Worth & 2.19 & (2.19) & 0.136 & 0.319 & 2.37 & (1.87) & 0.173 & 0.206 & -0.690 & $(1.94$ & -0.046 & 0.723 & 0.151 & (1.68) & 0.012 & 0.929 \\
\hline$F$ Test & \multirow{2}{*}{\multicolumn{4}{|c|}{$\begin{array}{l}1.90^{*} \\
0.088\end{array}$}} & \multirow{2}{*}{\multicolumn{4}{|c|}{$\begin{array}{l}1.91 * \\
0.089\end{array}$}} & \multirow{2}{*}{\multicolumn{4}{|c|}{$\begin{array}{c}3.07 * * \\
0.181\end{array}$}} & \multirow{2}{*}{\multicolumn{4}{|c|}{$\begin{array}{c}2.83 * * \\
0.164\end{array}$}} \\
\hline Adjusted $R^{2}$ & & & & & & & & & & & & & & & & \\
\hline
\end{tabular}


The results for $\mathrm{T} 2$ indicate that women have significantly higher exam $(b=6.29$, $p=0.014)$ and final grades $(b=0.539, p=0.015)$ than men and that whites have higher exam grades $(b=6.20, p=0.039)$ than non-whites. Although attitudes toward teachers is no longer significant in $\mathrm{T} 2(p=0.613, p=0.463)$ as it was in $\mathrm{T} 1$, those who have a more positive self-concept at $\mathrm{T} 2$ report better exam grades $(b=-4.31$, $p=0.045)$. This relationship with exam grades is the strongest $(\beta=-0.280)$ in the model compared to all of the other measures of statistics anxiety/attitudes for exam grades (ranging from $\beta=0.046$ to 0.117 ), as well as for final course grade $(\beta=-0.268)$.

The last exploratory research question asked whether change from T1 to T2 is associated with grades. The omnibus $\mathrm{F}$ test for both the exam grades $(F=1.512$, $p=0.32)$ and final grade $(F=1.784, p=0.061)$ are not statistically significant, suggesting that change is not significantly related to academic performance in this sample. Since the coefficients for the individual effects cannot be trusted when the omnibus test is not statistically significant, the results for that portion of the analysis are not shown.

\section{Discussion Summary of Findings}

The purpose of this study is to avoid over-diagnosing students with statistics anxiety thereby rendering it ubiquitous and meaningless. Rather, this study identifies the specific barriers that students face regarding statistics anxiety and attitudes by comparing mean levels across the STARS scales; examining whether these six dimensions of statistics anxiety/attitudes changed over the course of the semester; and analyzing whether levels and change varied by gender. In the analysis, I also explored whether the six STARS dimensions at the beginning and end of the semester predict academic performance, as well as whether changes in the types of anxiety/attitudes are associated with grades.

In summary, the main findings are that, first, both baseline and end of term exam anxiety is elevated compared to the other types. Second, the three types of anxiety significantly improve over the course of the semester, but attitudes are more stable. Third, women have significantly higher levels of anxiety and more negative attitudes, but their anxiety significantly improves by the end the semester and, in particular, their exam anxiety does so at a higher rate compared to men. Fourth, the exploratory regression models show different effects across the six STARS dimensions and the two outcomes at T1 and T2. Negative attitudes toward teachers at the beginning of the semester has an inverse relationship with both indicators of academic performance, and computational self-concept at the end of the semester is negatively related to exam grades. Change in anxiety/attitudes, however, is not a predictor of academic performance. Below I discuss these main findings in the 
context of offering specific aspects of statistics anxiety on which to focus pedagogical efforts so instructors can attempt to address statistics anxiety/attitudes if necessary, but also avoid over-diagnosing by not assuming that it applies to all students or all aspects of statistics classes.

\section{Avoiding Over-Diagnosis}

Rather than assuming that all students are at crisis levels of statistics anxiety, the results of this study show that students' beginning and end of term levels of anxiety stem primarily from exams. Thus, rather than assuming that students have an aversion to and a "considerable fear of anything with the slightest quantitative flavor to it" (Blalock 1987, 164), it would be helpful for statistics instructors to consider that, according to the results of this study, students' anxiety stems primarily from exams and that this type of anxiety significantly improves with exposure to the course, especially among women.

On the one hand, this study finds that statistics anxiety and negative attitudes are not universal across the STARS dimensions, but on the other hand, the majority of respondents (54.9\% at baseline) do in fact experience at least some anxiety concerning exams. This finding that students report the highest levels of exam anxiety compared to other types is consistent with prior research (Onwuegbuzie 1998; Onwuegbuzie and Wilson 2003; Haynes et al. 2004). Fortunately, ANOVA results also show that exam anxiety significantly improves by the end of the semester, especially for women, and further, regression results show no association between exam anxiety and academic performance. Decreasing exam anxiety may be a particularly important goal in order to help male students, as ANOVA results show women's exam anxiety decreases significantly more so than men's, although this may simply be because women's exam anxiety started off significantly higher.

In addition to exam anxiety significantly improving over the course of the semester, results show that while the other two types of anxiety measured here significantly improve by the end of the semester as well, the three types of attitudes do not. While this finding is consistent with other studies that show that attitudes do not change over the course of one semester (Townsend et al. 1998; Zieffler et al. 2008; Wismath and Worrall 2015; Lesser et al. 2016), it could also be a reflection that students' attitudes started off very positive, with the vast majority of respondents reporting positive attitudes toward their self-concept, statistics teachers, and the worth of statistics at baseline (ranging from $79 \%$ to $92 \%$ ). Perhaps negative attitudes are more stubborn to change than are positive attitudes. Future longitudinal research is needed to determine if attitudes really are more unlikely to change across the course of the semester than anxiety, or if attitudes can improve, at least with pedagogical strategies specifically designed to do so. 


\section{Gender and Self-Concept}

In addition to variation in mean levels and rates of change across the six dimensions of statistics anxiety/attitudes, there is also variation by gender, with women reporting significantly higher levels of exam and interpretation anxiety than men, as well as worse attitudes toward computational self-concept and worth of statistics. This finding that women report more anxiety and more negative attitudes about statistics than men is consistent with the majority of studies on the topic generally (Benson 1989; Bradley and Wygant 1998; DeCesare 2007; Rodarte-Luna and Sherry 2008; Condron et al. 2018;), as well as with findings on lower math selfconcept and less perceived value in statistics in particular (Macher et al. 2013). This finding is especially notable given that some scholars claim that low selfconfidence in one's math competence is a key reason why more women do not enter or stay in math and science fields (Zeldin and Pajares 2000).

On one hand, the contention that women's lower computational self-concept and interpretation anxiety represent actual gender differences in math abilities is unfounded (Bradley and Wygant 1998; Correll 2001; Macher et al. 2013). On the other hand, as the Thomas Theorem dictates, "if [people] define situations as real, they are real in their consequences" (Merton 1995, 380), which applies here in that perceptions can become reality; if women are more anxious because they perceive themselves to have poor math abilities, then those perceptions will manifest in the increased likelihood of indeed not being successful in math/statistics courses. Compared to men, results here do in fact support the claim that there is a gender "confidence gap," as women perceive themselves to have poorer math competency and more interpretation anxiety than men (Sadker and Sadker 1994), which is in alignment with past research (Campbell and Beaudry 1998; Correll 2001; DeCesare 2007; Condron et al. 2018). These findings are also consistent with the literature that documents a relationship between students' self-confidence and their academic performance in statistics courses (Finney and Schraw 2003; Marsh and Martin 2011; McGrath et al. 2015), as well as studies that show an inverse relationship between anxiety and self-esteem (Haynes et al. 2004; McGrath et al. 2015; Wismath and Worrall 2015; Condron et al. 2018). Unfortunately, ANOVA results here also show that students' computational self-concept does not significantly improve by the end of the semester, yet regression results indicate that students' end of term levels of self-concept are negatively associated with exam grades. Especially given that there is evidence that students' confidence in their math abilities can in fact improve over the course of the semester (Wismath and Worrall 2015), this study suggests that instructors may want to make concerted efforts to increase students' computational self-concept, especially among women who have more negative perceptions toward themselves and remain underrepresented in math and science fields (American Association of University Women 2019). 


\section{Academic Performance and Statistics Anxiety/Attitudes}

Even if attitudes do not change alongside exposure to the course, regression analyses suggest that statistics anxiety/attitudes may not matter much, at least in terms of grades. Thus, in addition to anxiety and negative attitudes not being universal, they also may not be as crippling to students as is sometimes assumed in the literature. The regression analyses show that the only type of baseline anxiety/attitudes associated with indicators of academic performance is fear of statistics teachers, which has an inverse relationship with both exam grades and final course grade. In one of the few studies to employ the STARS and focus on the important role of the teacher in reducing statistics anxiety, Williams (2010) found that all the six STARS anxiety/attitudes scales are related to various aspects of teacher immediacy, which refers to verbal and non-verbal behaviors that make people feel close to one another. From her findings she infers that teachers who show their students their "humanness" through practicing immediacy behaviors (e.g., smiling, calling students by name, making eye contact) may trigger a "safety signal" and subsequently reduce fear (Williams 2010, 12). Nonetheless, future research is needed to corroborate this study and Williams's that suggest fostering the teacher-student relationship, such as with immediacy behaviors, is an appropriate focal point for anxiety-reducing interventions.

Other than attitudes toward teachers at $\mathrm{T} 1$ and self-concept at $\mathrm{T} 2$, the regression analyses indicate that anxiety/attitudes are not associated with academic performance. This finding is inconsistent with the literature that documents a relationship between anxiety and learning (Rosenfeld 1978; Zeidner 1991; Onwuegbuzie and Wilson 2003; Chew and Dillon 2008) and with grades in particular (Fitzgerald et al. 1996). The lack of relationships between anxiety/attitudes and grades found here and in other studies (Lalonde and Gardner 1993; Zanakis and Valenzi 1997; Nasser 2004; Chiesi and Primi 2010) could be because anxious students compensate for their fear by studying more, resulting in higher grades. Studies that show the relationship between academic performance and anxiety may be more nuanced than is captured here support this possible explanation. For example, Keeley et al. (2008) show that there is an "optimal" level of anxiety for academic performance, as they identify a curvilinear relationship between the six dimensions of STARS constructs and test scores; both high and low anxiety are associated with low test scores, with mid-level anxiety producing the best test scores. Onwuegbuzie and Seaman (1995) find the opposite effect in that both low and high anxiety students earn higher grades on an untimed exam. In addition to the moderation effects described by Keeley et al. (2008) and Onwuegbuzie and Seaman (1995), statistics anxiety may also play a mediating role, as anxiety appears to mediate the relationship between a number of factors and exam grades, including number of statistics courses taken, study habits, and course load (Onwuegbuzie 2003). More research is needed to determine if statistics 
anxiety/attitudes have a strong and robust relationship with various indicators of academic performance such as grades, as well as with other outcomes such as students' enjoyment of the course and overall well-being. Additional research should also examine if the timing of the assessment of anxiety (e.g., beginning, middle, end of semester) accounts for variation in the relationship between statistics anxiety/attitudes and academic performance, as studies including this one suggest they do (Zanakis and Valenzi 1997; Wisenbaker et al. 2000).

\section{Conclusions Limitations}

This study was largely exploratory and descriptive and, therefore, generalizability of these findings is compromised for several reasons, most notably because the data were all collected in classes taught by the same professor. Additionally, this was not a random sample and all data were collected at one urban Midwestern university that is not representative of all colleges/students. Socio-demographic variables that are known to be correlated with statistics anxiety, such as age and socio-economic status (Onwuegbuzie and Wilson 2003), were not collected. Readers should also interpret the findings regarding gender with caution, as there are substantially more women than men in the sample.

In addition to socio-demographics, there are a few other potential correlates that I was not able to control for, namely some measure of prior academic achievement. There is evidence that academic ability, such as reading ability (Collins and Onwuegbuzie 2007), previous math experience (Baloğlu 2003), and previous grades in statistics courses (Zanakis and Valenzi 1997), is associated with statistics anxiety. Furthermore, even with the longitudinal data employed here, it is not possible to establish the causal order in that grades and anxiety likely function in a feedback loop in which prior math performance and ability exacerbates anxiety levels, which in turn likely negatively affects academic performance and the learning of math/statistics skills.

Another limitation is that, for three reasons, levels of anxiety in this study may be underestimated. First, from the very first time I taught Social Statistics in Fall 2015, I heeded the warnings of colleagues and teaching and learning scholarship regarding statistics anxiety and structured the course accordingly. Second, as to maximize the response rate, I administered the Time 1 survey after the add/drop date after the first week of class. Therefore, students were already exposed to me and the class structure, as well as my spiel about how the course is not a math class and all the things I do to mitigate anxiety (especially pertaining to exams) so they can focus on learning. Third, there may be a selection effect in that those with the most crippling anxiety and negative attitudes may have dropped the course in week one before Time 1 data collection or before the last week of class at Time 2 . Readers 
should also keep in mind the results of the missing data analysis that showed poorer and more anxious students were more likely to be selected out of the sample. Conversely, levels of statistics anxiety may be overestimated compared to other studies because of the student population of this sample. Students at this metropolitan state college may be more likely to have anxiety around rigorous courses such as statistics than their more socio-economically privileged counterparts (DeCesare 2007).

\section{Contributions}

Despite its limitations, this study makes several important contributions to the literature on statistics anxiety, as it uses longitudinal data with a comprehensive survey instrument that assesses statistics attitudes/anxiety as the independent variables and actual grades (as opposed to perceived grades) as the dependent variables. While this study corroborates the findings of other studies, such as the high levels of exam anxiety and women's elevated rates of anxiety and negative attitudes toward statistics, it also challenges widespread anecdotal assumptions about the pervasiveness and effects of all types of statistics anxiety. Furthermore, this study suggests that while anxiety tends to decrease by the end of the semester, attitudes toward statistics may be relatively stable regardless of exposure to the course. Finally, the exploratory regression analyses indicate that the timing of the assessment of statistics anxiety/attitudes may matter in that results show that fear of statistics teachers is salient for academic performance at the beginning of the semester, while students' self-concept at the end of the semester is associated with exam grades. This study was also the first to my knowledge to employ change in statistics anxiety/attitudes as the independent variable and provides preliminary evidence that change is not a predictor of academic performance. Future research is needed to confirm results here and examine outcomes of statistics anxiety other than academic performance.

Based on the results of this study, if statistics instructors desire to reduce statistic anxiety in their classes, they might want to pay particular attention to elevated rates of exam anxiety compared to other types of statistics anxiety/attitudes; the stability of attitudes over the course of the semester; women's increased levels of anxiety and negative attitudes compared to men; students' computational self-concept, especially women's; and the inverse association between fear of statistics teachers and academic performance. If statistics instructors address these specific barriers rather than over-diagnosing statistics anxiety by assuming it applies to all students and all types of perceptions, then perhaps students will be more likely to successfully pass the class and graduate, and - arguably most importantly - gain the valuable quantitative literacy skills that are important for a democratic society. 


\section{Acknowledgment}

I greatly appreciate the constructive feedback from the anonymous reviewers, as well as from Drs. Julie Pelton, Daniel Hawkins, and Susan Roxburgh for reading earlier drafts of this manuscript. I would also like to thank Dr. Jonathan Santo for his assistance with the analysis, as well as the students for participating in the study.

\section{References}

Allison, Paul D. 2001. Missing data. Vol. 136. Thousand Oaks, CA: Sage publications.

American Association of University Women. 2019. www.aauw.org

Baloğlu, Mustafa. 2002. "Psychometric Properties of the Statistics Anxiety Rating Scale.” Psychological Reports, 90(1): 315-25. https://doi.org/10.2466/pr0.2002.90.1.315

Baloğlu, Mustafa. 2003. "Individual Differences in Statistics Anxiety among College Students." Personality and Individual Differences, 34(5): 855-865. https://doi.org/10.1016/S0191-8869(02)00076-4

Baloğlu, Mustafa, and P.F. Zelhart. 2003. "Statistical Anxiety: A Detailed Review." Psychology and Education, 40: 27-37.

Benson, Jeri. 1989. "Structural Components of Statistical Test Anxiety in Adults: An Exploratory Model." The Journal of Experimental Education, 57(3): 24761. https://doi.org/10.1080/00220973.1989.10806509

Benson, Jeri, Deborah Bandalos, and Susan Hutchinson. 1994. "Modeling Test Anxiety among Men and Women." Anxiety, Stress, and Coping, 7(2): 13148. https://doi.org/10.1080/10615809408249340

Blalock, Jr., Hubert M. 1987. "Some General Goals in Teaching Statistics." Teaching Sociology, 15(2): 164-72. https://doi.org/10.2307/1318031

Bradley, Drake R., and Catherine R. Wygant. 1998. "Male and Female Differences in Anxiety about Statistics Are Not Reflected in Performance." Psychological Reports, 82(1): 245-6. https://doi.org/10.2466/pr0.1998.82.1.245

Campbell, James R., and Jeffrey S. Beaudry. 1998. "Gender Gap Linked to Differential Socialization for High-Achieving Senior Mathematics Students." The Journal of Educational Research, 91(3): 140-47. https://doi.org/10.1080/00220679809597534

Chew, Peter, and Denise B. Dillon. 2014. "Statistics Anxiety Update: Refining the Construct and Recommendations for a New Research Agenda." Perspectives on Psychological Science, 9(2): 196-208. https://doi.org/10.1177/1745691613518077 
Chiesi, Francesca, and Caterina Primi. 2010. "Cognitive and Non-Cognitive Factors Related to Students' Statistics Achievement." Statistics Education Research Journal, 9(1): 6-26.

Chiou, Chei-Chang, Yu-Min Wang, and Li-Tze Lee. 2014. "Reducing Statistics Anxiety and Enhancing Statistics Learning Achievement: Effectiveness of a One-Minute Strategy." Psychological Reports, 115(1): 297-310. https://doi.org/10.2466/11.04.PR0.115c12z3

Cohen, Jacob. 1988. Statistical Power Analysis for the Behavioral Sciences (2nd ed.). Hillsdale, NJ: Erlbaum.

Collins, Kathleen M.T., and Anthony J. Onwuegbuzie. 2007. "I Cannot Read My Statistics Textbook: The Relationship between Reading Ability and Statistics Anxiety." The Journal of Negro Education, 76(2): 118-129.

Condron, Dennis J., Jacob H. Becker, and Linda Bzhetaj. 2018. "Sources of Students' Anxiety in a Multidisciplinary Social Statistics Course." Teaching Sociology, 46(4): 346-55. https://doi.org/10.1177/0092055X18780501

Correll, Shelley J. 2001. "Gender and the Career Choice Process: The Role of Biased Self-Assessments." American Journal of Sociology, 106(6): 16911730. https://doi.org/10.1086/321299

Cruise, Robert J., R. William Cash, and David L. Bolton. 1985. "Development and Validation of an Instrument to Measure Statistical Anxiety." American Statistical Association Proceedings of the Section on Statistical Education. 4(3).

DeCesare, Michael. 2007. “'Statistics Anxiety” among Sociology Majors: A First Diagnosis and Some Treatment Options." Teaching Sociology, 35(4): 36067. https://doi.org/10.1177/0092055X0703500405

Deckard, Natalie Delia. 2017. "Statistics Education for Undergraduate Sociology Majors: Survey Findings across Institutions.” Numeracy, 10(2) :1-17. https://doi.org/10.5038/1936-4660.10.2.8

Finney, Sara J., and Gregory Schraw. 2003. "Self-efficacy Beliefs in College Statistics Courses." Contemporary Educational Psychology, 28(2): 161-186. https://doi.org/10.1016/S0361-476X(02)00015-2

Fitzgerald, Shawn M., Stephen J. Jurs, and Lynne M. Hudson. 1996. "A Model Predicting Statistics Achievement among Graduate Students." College Student Journal, 30(3): 361-66.

Hanna, Donncha, Mark Shevlin, and Martin Dempster. 2008. "The Structure of the Statistics Anxiety Rating Scale: A Confirmatory Factor Analysis Using UK Psychology Students." Personality and Individual Differences, 45(1): 68-74. https://doi.org/10.1016/j.paid.2008.02.021

Haynes, Ada F., Anita G. Mullins, and Barry S. Stein. 2004. "Differential Models for Math Anxiety in Male and Female College Students." Sociological Spectrum, 24(3): 295-318. https://doi.org/10.1080/02732170490431304 
Hedges, Sarai. 2017. "Statistics Student Performance and Anxiety: Comparisons in Course Delivery and Student Characteristics." Statistics Education Research Journal, 16(1): 320-336.

Keeley, Jared, Ryan Zayac, and Christopher Correia. 2008. "Curvilinear Relationships between Statistics Anxiety and Performance among Undergraduate Students: Evidence for Optimal Anxiety." Statistics Education Research Journal, 7(1): 4-15.

Lalonde, Richard N., and Robert C. Gardner. 1993. "Statistics as a Second Language? A Model for Predicting Performance in Psychology Students." Canadian Journal of Behavioural Science/Revue canadienne des sciences du comportement, 25(1): 108-125. https://doi.org/10.1037/h0078792

Lesser, Lawrence M., Dennis K. Pearl, and John J. Weber III. 2016. "Assessing Fun Items' Effectiveness in Increasing Learning of College Introductory Statistics Students: Results of a Randomized Experiment." Journal of Statistics Education, 24(2): 54-62. https://doi.org/10.1080/10691898.2016.1190190

Liu, Shujie, Anthony J. Onwuegbuzie, and Lingqi Meng. 2012. "Examination of the Score Reliability and Validity of the Statistics Anxiety Rating Scale." The Journal of Educational Enquiry, 11(1): 29-42.

Macher, Daniel, Manuela Paechter, Ilona Papousek, Kai Ruggeri, H. Harald Freudenthaler, and Martin Arendasy. 2013. "Statistics Anxiety, State Anxiety during an Examination, and Academic Achievement." British Journal of Educational Psychology, 83(4): 535-549. https://doi.org/10.1111/j.2044-8279.2012.02081.x

Marsh, Herbert W., and Andrew J. Martin. 2011. "Academic Self- Concept and Academic Achievement: Relations and Causal Ordering." British Journal of Educational Psychology, 81(1): 59-77. https://doi.org/10.1348/000709910X503501

McGrath, April L., Alyssa Ferns, Leigh Greiner, Kayla Wanamaker, and Shelley Brown. 2015. "Reducing Anxiety and Increasing Self-efficacy within an Advanced Graduate Psychology Statistics Course." Canadian Journal for the Scholarship of Teaching and Learning, 6(1): 1-17. https://doi.org/10.5206/cjsotl-rcacea.2015.1.5

Merton, Robert K. 1995. “The Thomas Theorem and the Matthews Effect." Social Forces 74(2): 379-424. https://doi.org/10.2307/2580486

Nasser, Fadia M. 2004. "Structural Model of the Effects of Cognitive and Affective Factors on the Achievement of Arabic-Speaking Pre-Service Teachers in Introductory Statistics." Journal of Statistics Education, 12(1): 1-19. https://doi.org/10.1080/10691898.2004.11910717 
Onwuegbuzie, Anthony John. 1995. "Statistics Test Anxiety and Female Students." Psychology of Women Quarterly, 19(3): 413-418. https://doi.org/10.1111/j.1471-6402.1995.tb00083.x

Onwuegbuzie, Anthony J. 1998. "The Dimensions of Statistics Anxiety: A Comparison of Prevalence Rates among Mid-Southern University Students." Louisiana Educational Research Journal, 23(2): 23-40.

Onwuegbuzie, Anthony J. 1999. "Statistics Anxiety among African American Graduate Students: An Affective Filter?" Journal of Black Psychology, 25(2): 189-209. https://doi.org/10.1177/0095798499025002004

Onwuegbuzie, Anthony J. 2003. "Modeling Statistics Achievement among Graduate Students." Educational and Psychological Measurement, 63(6): 1020-38. https://doi.org/10.1177/0013164402250989

Onwuegbuzie, Anthony J. 2004. "Academic Procrastination and Statistics Anxiety." Assessment \& Evaluation in Higher Education, 29(1): 3-19. https://doi.org/10.1080/0260293042000160384

Onwuegbuzie, Anthony J., and Michael A. Seaman. 1995. "The Effect of Time Constraints and Statistics Test Anxiety on Test Performance in a Statistics Course." The Journal of Experimental Education, 63(2): 115-24. https://doi.org/10.1080/00220973.1995.9943816

Onwuegbuzie, Anthony J., and Vicki A. Wilson. 2003. "Statistics Anxiety: Nature, Etiology, Antecedents, Effects, and Treatments-A Comprehensive Review of the Literature." Teaching in Higher Education, 8(2): 195-209. https://doi.org/10.1080/1356251032000052447

Papousek, Ilona, Kai Ruggeri, Daniel Macher, Manuela Paechter, Moritz Heene, Elisabeth M. Weiss, Günter Schulter, and H. Harald Freudenthaler. 2012. "Psychometric Evaluation and Experimental Validation of the Statistics Anxiety Rating Scale.” Journal of Personality Assessment, 94(1): 82-91. https://doi.org/10.1080/00223891.2011.627959

Paxton, Pamela. 2006. "Dollars and Sense: Convincing Students that They Can Learn and Want to Learn Statistics.” Teaching Sociology, 34(1): 65-70. https://doi.org/10.1177/0092055X0603400106

Rodarte-Luna, Bertha, and Alissa Sherry. 2008. "Sex Differences in the Relation between Statistics Anxiety and Cognitive/Learning Strategies." Contemporary Educational Psychology, 33(2): 327-44. https://doi.org/10.1016/j.cedpsych.2007.03.002

Rosenfeld, Rachel Ann. 1978. "Anxiety and Learning." Teaching Sociology, 5(2): 151-66. https://doi.org/10.2307/1317061

Sadker, M., and D. M. Sadker. 1994. Failing at Fairness: How America's Schools Cheat Girls. New York: Scribner. 
Schacht, Steven, and Brad J. Stewart. 1990. "What's Funny about Statistics? A Technique for Reducing Student Anxiety.” Teaching Sociology, 18(1): 5256. https://doi.org/10.2307/1318231

Townsend, Michael A.R., Dennis W. Moore, Bryan F. Tuck and Keri M. Wilton. 1998. "Self- Concept and Anxiety in University Students Studying Social Science Statistics within a Co- Operative Learning Structure." Educational Psychology, 18(1): 41-54. https://doi.org/10.1080/0144341980180103

Van Gundy, Karen, Beth A. Morton, Hope Q. Liu, and Jennifer Kline. 2006. "Effects of Web-Based Instruction on Math Anxiety, the Sense of Mastery, and Global Self-Esteem: A Quasi-Experimental Study of Undergraduate Statistics Students.” Teaching Sociology, 34(4): 370-88. https://doi.org/10.1177/0092055X0603400404

Walsh, J. J., and G. Ugumba-Agwunobi. 2002. "Individual Differences in Statistics Anxiety: The Roles of Perfectionism, Procrastination and Trait Anxiety." Personality and Individual Differences, 33(2): 239-251. https://doi.org/10.1016/S0191-8869(01)00148-9

Williams, Amanda S. 2010. "Statistics Anxiety and Instructor Immediacy." Journal of Statistics Education, 18(2):1-18. https://doi.org/10.1080/10691898.2010.11889495

Williams, Amanda S. 2013. "Worry, Intolerance of Uncertainty, and Statistics Anxiety." Statistics Education Research Journal, 12(1): 48-59.

Wisenbaker, Joseph M., Janice S. Scott, and Fadia Nasser. 2000. "Structural Equation Models Relating Attitudes about and Achievement in Introductory Statistics Courses: A Comparison of Results from the US and Israel." 9th International Congress on Mathematics Education. Tokyo, Japan.

Wismath, Shelly L., and Alyson Worrall. 2015. "Improving University Students' Perception of Mathematics and Mathematics." Numeracy, 8(1): 1-17. https://doi.org/10.5038/1936-4660.8.1.9

Zanakis, Stelios H. and Enzo R. Valenzi. 1997. "Student Anxiety and Attitudes in Business Statistics.” Journal of Education for Business, 73(1): 10-16. https://doi.org/10.1080/08832329709601608

Zeidner, Moshe. 1990. "Does Test Anxiety Bias Scholastic Aptitude Test Performance by Gender and Sociocultural Group?" Journal of Personality Assessment, 55(1): 145-60. https://doi.org/10.1080/00223891.1990.9674054

Zeidner, Moshe. 1991. "Statistics and Mathematics Anxiety in Social Science Students: Some Interesting Parallels." British Journal of Educational Psychology, 61(3): 319-28. https://doi.org/10.1111/j.2044-8279.1991.tb00989.x

Zeldin, Amy L., and Frank Pajares. 2000. "Against the Odds: Self-efficacy Beliefs of Women in Mathematical, Scientific, and Technological Careers." 
American Educational Research Journal, 37(1): 215-246.

https://doi.org/10.3102/00028312037001215

Zieffler, Andrew, Joan Garfield, Shirley Alt, Danielle Dupuis, Kristine Holleque, and Beng Chang. 2008. "What Does Research Suggest about the Teaching and Learning of Introductory Statistics at the College Level? A Review of the Literature." Journal of Statistics Education, 16(2).

https://doi.org/10.1080/10691898.2008.11889566 